\title{
TEACHING VERB SPELLING THROUGH EXPLICIT DIRECT INSTRUCTION
}

\author{
ROBERT J.P.M. CHAMALAUN*, ANNA M.T. BOSMAN** AND \\ MIRJAM T.C. ERNESTUS*
}

\author{
* Centre for Language Studies, Radboud University \\ ** Behavioural Science Institute, Radboud University
}

\begin{abstract}
Homophonous verb forms are notoriously difficult to spell. Two intervention studies - one with secondaryschool students and one with university students - compared the effectiveness of an Explicit Direct Instruction (EDI) teaching approach that was very interactive with traditional instruction (TI) on Dutch homophonous verb spelling. The two approaches differ in the attention dedicated to the identification of the grammatical functions of verb forms and in the teacher's guidance of the students, which affects the interactivity during the classes. Students were pre-tested and post-tested on their knowledge of grammar and spelling of homophonous verb forms embedded in sentences. Both the EDI and the TI courses consisted of 4.5 hours of training. Secondary-school students' verb-spelling performance improved, irrespective of the type of instruction. University students' verb-spelling performance increased after both interventions, probably resulting from their improved grammatical knowledge. Importantly, the EDI students' performance increased more than the TI students' performance because the EDI students had learnt to rely more on their grammatical knowledge or make better use of their increased grammatical mastery. These results are in line with our hypothesis that the explicit interactivity that is inherent to EDI is beneficial for teaching verb spelling to students beyond primary-school level, who already possess some grammatical knowledge.
\end{abstract}

Keywords: verb spelling; spelling instruction; EDI; grammar; homophony

Chamalaun, R.J.P.M., Bosman, A.M.T., \& Ernestus, M.T.C. (2022). Teaching verb spelling through explicit direct instruction. L1-Educational Studies in Language and Literature, 20, 128. https://doi.org/10.21248/l1esll.2022.22.1.379

Corresponding author: Robert J.P.M. Chamalaun, PO Box 9103, 6500 HD Nijmegen, the Netherlands, email: robert.chamalaun@ru.nl @ 2020 International Association for Research in L1Education. 


\section{INTRODUCTION}

Spelling in alphabetic languages transforms orally presented information, that is, sounds (i.e., phonemes) into visual codes (i.e., graphemes). The vast majority of words show unique sound-spelling coupling (e.g., stop and star in English). Nevertheless, an important number of words with different meanings sound identical but are spelled differently. An English example is the word/sent/, which has at least three different meanings and three different corresponding spellings: <sent> (past participle of the verb to send), <cent> (one hundredth of a standard decimal currency), and <scent> (smell or fragrance). These words are referred to as lexical homophones, because the difference in spelling is determined by the meaning of the word.

The English language is notorious for its complex orthography and the number of homophones (e.g., Scholfield, 1994). Lexical homophones can also be found in other languages, among others, Dutch and French. However, the number and difficulty of lexical homophones in these languages are relatively limited compared to these languages' grammatically-determined homophones, particularly dominant in verbal paradigms, where the grammatical function of the verb form determines how the word is spelled. For instance, French /авivə/ is spelled as <arrive>, <arrives> or <arrivent $>$ depending on whether it functions as the first person singular, the second person singular or the third person plural of the verb arriver 'to arrive', respectively. The only way to spell homophonous verb forms correctly is to make a proper grammatical analysis and subsequently apply the corresponding spelling rules.

Several studies have shown that spellers often confuse homophone members of a verb paradigm, such as in Danish, Dutch, French, Greek, and Portuguese, which suggests that spellers do not always make a proper analysis or do not know the relevant rules or their application (e.g., Bryant et al., 1999; Juul \& Ebro, 2004; Largy et al., 1996; Sandra et al., 1999). This study compares the effectiveness of two teaching strategies for verb spelling for secondary-school and university students.

When children learn to spell, they are first confronted with words that are consistent in their phoneme-to-grapheme correspondence. For example, the English word $\operatorname{dog}$ consists of the phonemes $/ \mathrm{d} /, / \mathrm{p} /, / \mathrm{g} /$. The phoneme $/ \mathrm{d} /$ corresponds to the grapheme $\langle\mathrm{d}\rangle$, the $/ \mathrm{b} /$ to $\langle 0\rangle$, and $/ \mathrm{g} /$ to $\langle\mathrm{g}\rangle$. In this example, the application of simple phoneme-to-grapheme mappings suffices. Children thus learn to adhere to the phonological principle 'spell what you hear' (Read, 1986). When the spelling of the language also adheres to the morphological principle, children start learning this principle when they grow older. It prescribes the spelling of a morpheme to remain constant across the words in which it occurs, despite variations in pronunciation, as in heal-health. The morphological principle can thus override the phonological principle. As a consequence, it may give rise to members of a homophonous verb-form pair being spelled differently because the morpheme reflecting the form's grammatical function (tense, person, etc.) has to be spelled identically in all verbs. For example, in Dutch, the spelling of the present tense first and third person singular of the 
verb wenden 'to turn' are both pronounced/uent/, but are spelled <wend> and $<w e n d t>$, respectively, with an additional $<t>$ in the third person because this $/ t /$ is audible in third person singular present tense forms with stems not ending in $/ d /$ or / $t$ / (as in /verkt/, the third person singular present tense of the verb werken to work').

The prevalence of the morphological principle in verb spelling implies that verbspelling instruction supposes grammatical awareness: Only when spellers can identify the grammatical function of the word, they can properly spell the word. Indeed, several studies have documented a strong relationship between grammatical awareness and spelling proficiency (e.g., Chamalaun et al., 2021; Juul \& Ebro, 2004; Juul, 2005; Muter \& Snowling, 1997; Nunes et al., 1997).

Several spelling strategies are possible. Here, we focus only on the strategy using an algorithm, which consists of a flowchart of yes-no grammatical questions. This strategy requires spellers to determine the grammatical and morphological properties of the target verb form and to then apply the corresponding spelling rule to arrive at the correct spelling. In Dutch, the use of an algorithm in verb spelling has been proven an effective spelling strategy (e.g., Assink, 1987; Zuidema, 1988). It is widely used in Dutch classrooms, albeit its popularity seems to be declining (Bakker-Peters et al., 2017).

However, most textbooks do not specifically prescribe what verb-spelling instruction and strategy should be used. This often leads to decreased attention to the identification of verb forms' grammatical functions although they are crucial for the application of the spelling rules. In general, attention for grammar in relation to verb spelling has been minimized in the recent past, due to, among others, the strong focus on communicative language teaching, particularly in secondary schools, where verb-spelling instruction is mainly focused on elaborating on knowledge acquired in primary schools. This led to instructional practices, henceforth referred to as traditional verb-spelling instruction (henceforth: $\mathrm{TI}$ ), that implicitly assume that spellers know the relevant grammatical concepts. Rather than integrating the teaching of the grammatical concepts and the appropriate spelling rules at all times, traditional verbspelling instruction usually focuses mainly on the orthographical rules. This diminished attention for grammar led, for instance in France, to adjustments in the recently published high school curriculum. Teachers in France are now explicitly required to teach grammar in their lessons and to discuss grammatical analyses with students from ninth grade (Bosse et al., 2020).

This study investigates whether the combination of a more explicit attention for grammar and spelling yields better verb-spelling results than traditional verbspelling instruction among students who already have some basic grammatical knowledge. Although both traditional verb-spelling instruction and explicit verbspelling instruction causes students to acquire a certain level of verb-spelling proficiency, it is not clear which instruction method is superior for students who already have some grammatical knowledge (i.e., secondary-school and university students). 
To compare the effectiveness of these two instructional strategies, we conducted two intervention studies.

\subsection{Explicit instruction}

In general, there are two views on explicit teaching, which can be placed on a scale with direct instructional guidance at the one end and minimal guidance approach at the other end of the continuum (Hollingsworth \& Ybarra, 2009). The latter has been called by various names, but the pedagogical approach is essentially the same. The past half-century of empirical research on this issue has provided overwhelming and unambiguous evidence that minimal guidance during instruction is significantly less effective and efficient than guidance specifically designed to support the cognitive processing necessary for learning (Kirscher et al., 2006).

The importance of explicit and systematic instruction has become a central element of discussions of effective instruction. Explicit instruction origins from research conducted by Engelmann and colleagues in the 1960s (see Adams \& Engelmann, 1996). Their Direct Instruction model (often referred to as DI, with capitals) is a scripted instructional model (for an overview, see Engelmann \& Carnine, 1991). Please note that the more generic term direct instruction (with lower-case letters) usually refers to a broad set of educational programs that incorporate elements of systematic or explicit instruction (Stockard et al., 2018).

Over the past decades, the body of literature on the effectiveness of DI has increased tremendously. In their meta-analysis of over 300 published studies on the effectiveness of DI over the last fifty years, Stockard et al. (2018) found solely positive effects on learning outcomes and skills. These effects were found for various groups of students, including low performers (Adams \& Engelmann, 1996). As Liem and Martin (2013) point out, a review by Hattie (2009) shows that implementation of DI involves seven carefully organized major steps: the teacher (1) communicates the learning goals and orients the students to learn, (2) examines whether the students possess the knowledge and skills needed to understand the new lesson, (3) presents the key principles of the new lesson through clear instruction, (4) checks the students' mastery and understanding by posing questions, providing examples, and correcting misconceptions, (5) provides opportunities for guided practice, (6) assesses the students' performance and provides feedback on the guided practice, and (7) provides opportunities for independent practice through group or individual work in class or homework. Thus, guided intensive learning, in the form of deliberate practice and worked examples, is at the heart of DI.

Lately, the model of DI has been further developed into a more elaborated model, referred to as Explicit Direct Instruction (henceforth referred to as EDI), which can be considered a refinement of Direct Instruction supplemented with additional techniques. This means that EDI is not a strategy per se, but rather a combination of several explicit instructional strategies. EDI thus consists of a number of fixed lesson components, supplemented with a number of specific techniques (see Hollingsworth 
\& Ybarra, 2009). For those who are not familiar with EDI, we will first describe the components, after which we will detail the techniques used in EDI lessons.

\section{$1.2 E D I$}

One of the components of EDI concerns the start of each lesson. The teacher shares the learning objective, that is, shows what is expected from students to know at the end of the lesson. The learning objective is defined concretely so that it can be determined at the end of the lesson whether the students have achieved the learning goal (Marzano et al., 2001). An example of a leaning objective is: "I can determine the verb in a sentence". In addition, prior knowledge is activated in order to establish a connection between what students already know and the newly offered material.

A second component deals with teaching the concept and the necessary skills to handle that concept. The concept is the main idea or the core of the lesson. Both the concept and the skills are described in the learning objective of the lesson. For instance, the skill to determine the verb in a sentence is to ask oneself the question: "Which word describes an action in the sentence (or describes the subject)?". Clearly defining the concept guides students in how to generalize what they learn from one example to similar cases, thereby further developing their meta-cognitive skills. Of course, enough examples should be given to ensure that students recognize the concept in different contexts, and to make sure that the students develop the skills to handle the concept.

A third component concerns guided practice, as proposed by Rosenshine (2012). After the instruction, the concept and the skills are practiced jointly with the teacher, with responsibility being gradually transferred to the students. First, the teacher demonstrates, then the teacher and the students work jointly, subsequently the students practice with one another, usually in pairs, and finally the students perform the steps independently. This process of gradual release of responsibility is described by Pearson and Gallagher (1983). The critical stage in this model is the guided practice. The goal of the model is that all students get to the point where they are able to accept total responsibility for the task, including the responsibility for determining whether or not the strategy is applied appropriately (i.e., self-monitoring). At the same time, the model assumes that students will need some guidance in reaching that stage of independence and that it is precisely the teacher's role to provide such guidance.

Prior to the phase of independent processing an extra closure follows. The teacher carries out a final check to determine which students master the concepts and skills that were taught and which students have not yet attained the necessary skills to work independently and therefore require extended instruction. Students who have the required knowledge and skills will proceed to the next phase. The goal of assignments in the phase of independent processing is to ensure that students incorporate the concept and skills through ample repetition into long-term memory. In the meantime, students who not yet fully master the concepts and skills that were 
taught, receive extended instruction, following the same procedure as regular instruction. If necessary, the teacher uses smaller steps to explain the subject matter.

An EDI lesson ends by reflecting on the learning objective. Feedback is given on the process, including the students' work attitude. The students are also asked what they have learnt and what they found easy and difficult. Finally, a preview of the next lesson is provided.

EDI uses a set of instructional techniques, throughout the entire lesson, that has proven to be effective. One of the teaching techniques is using modelling/thinkalouds to make the concept explicit by "showing" (i.e., key physical actions) and "telling" (i.e., thinking aloud) students how to solve a problem or complete a task, that is, how to apply the concept in context (e.g., Blair \& Rupley, 1988). In other words, modelling is a teaching technique that teachers can use to help students conceptualize concepts and skills (e.g., Rupley et al., 2009). Proper application of this principle along with sufficient practice, helps students to adopt the strategy and store it in long-term memory.

Another technique deals with checking students' understanding of the topic. The student's mastery is continuously being checked. The teacher asks questions to the entire class and gives all students time to think about their answers. EDI does not require students to raise their hands if they want to give the answer; the teacher randomly picks one or several students. Based on the students' responses, the teacher can immediately adjust the instruction. Moreover, students can hear the same good answer several times, which enables better understanding of the subject (Hollingsworth \& Ybarra, 2009). In case a wrong answer is given, the teacher immediately corrects the error, which is particularly important because unlearning ingrained errors is hard and time-consuming (Wolfe, 1998).

An important feature of EDI is to encourage all students to participate. One technique is the use of small whiteboards, on which students write their answers and which they collectively show to the teacher. This way, the teacher can, on the one hand, check whether the students understand what is being taught, and, on the other, ensure that all students participate actively. The stimulation of students' active participation not only enhances individual learning performance, but also contributes to experiences of success for all students.

A final technique is that the teacher provides process-oriented feedback (e.g., "You can change the time of the sentence to find present tense or past tense verb forms"), which relates to performance rather than the person (Shute, 2008). Processoriented feedback not only enables the teacher to monitor students' comprehension, it may also advance the students' sense of competence. Process-oriented feedback has proven to be effective (Hattie, 2009).

The effectiveness of explicit instruction is supported by the existence of a large volume of convergent research, conducted over almost five decades, and emanating from a variety of disciplines and theories (Hughes et al., 2017). The results of research on effective teaching show that the systematic presentation of material in small steps, evaluation of student understanding, and elicitation of active 
participation on the part of the students, is a successful approach for the teaching of reading and mathematics in primary and secondary school (Veenman et al., 2003). Hänze and Berger (2007) also compared cooperative instruction with traditional instruction and they found that traditional direct instruction has a facilitating effect on physics performance. Furthermore, positive effects of direct instruction have been found for social studies. A study by Fielding et al. (1983), for instance, showed that direct instruction produced significantly higher scores on both a multiple-choice test and an essay test requiring the application of unfamiliar cases to the constitutional principles taught.

\subsection{The present study}

To our knowledge, no research has been conducted addressing the effectiveness of EDI on verb spelling. Furthermore, most research on EDI focussed on primary-school education as the model is particularly useful for novices. However, chances are that the positive effects of EDI also apply to verb spelling. We investigate whether basic and experienced spellers benefit more from spelling courses taught with EDI, and that reintroduces the necessary grammatical concepts and that is very interactive, than traditional spelling courses. We focus on secondary-school students and university students.

The present study investigates the acquisition of the grammatically-determined spelling of homophonous verb spelling in Dutch. Dutch children learn the verbspelling system when they are rather young (around nine or ten years of age) and the rules are being rehearsed extensively throughout their formative school years. From a descriptive point of view, the complexity of the spelling rules seems relatively low compared to French, for instance, as they can largely be characterized as morphographic (concatenating the stem and adding one or multiple suffixes). Nevertheless, despite the amount of educational energy invested in spelling rules, empirical evidence shows that also in Dutch many errors are made with homophonous verb forms (e.g., Assink, 1985; Bosman, 2005; Sandra et al., 1999, 2004).

We conducted the same intervention study with two different groups of students: secondary-school students (Experiment 1) and university students (Experiment 2). The former group can be considered basic spellers, whereas the latter are experienced spellers. In both experiments, a quasi-experimental design of pretest, verb-spelling course, and posttest was conducted. Students were first pre-tested on their knowledge of grammar and verb spelling, and subsequently subjected to a verb-spelling course that used either traditional verb-spelling instruction ( $\mathrm{TI})$, or explicit verb-spelling instruction (EDI). Both TI and EDI used an algorithmic approach in verb spelling. Afterwards, students were post-tested on the same target verb forms as in the pretest, but embedded in different sentences. The training sessions and the tests were conducted by the first author of this paper. We expected that students who were given EDI lessons became more proficient in applying the verb-spelling rules than those who were taught with $\mathrm{TI}$, that is, we expected that improvement in 
grammatical mastery led to more improvement in verb spelling for EDI students than for Tl students.

\section{EXPERIMENT 1}

\subsection{Method}

\subsubsection{Participants}

Thirty-eight secondary-school students (16 boys, 22 girls) between the age of 14 and 18 years $(M=15.6$ years, $S D=0.94)$ participated in the study. ${ }^{1}$ All students were native speakers of Dutch, and attended grade 10 (i.e., the fourth year) of havo (i.e., a level of five-year training that gives access to higher education, polytechnics) at a school for secondary education. None of the students suffered from dyslexia. The experiment was approved by the Ethics Assessment Committee for the Humanities of Radboud University. The children's parents also gave their approval. We used a quasi-experimental design which means that each group (i.e., existing school classes) was randomly assigned to either the experimental condition (EDI) or the control condition (TI). The group that followed the TI verb-spelling course consisted of 21 students, whereas the group that followed the EDI verb-spelling course consisted of 17 students. They were unaware of the condition they were assigned to. Masking was enforced by using EDI in the TI group for another subject in the curriculum, namely writing instruction. If children of both groups would talk to each other about the content of their courses, they both would have experience with EDI. All students participated both in the pretest and the posttest. Unfortunately, four students in the EDI condition missed two of the six training sessions.

\subsubsection{Materials}

The materials for the pretest and posttest were taken from Chamalaun et al. (2021), which contained a total of 72 test verbs (see the Appendix). For half of the test verbs, the third person singular present tense is homophonic with the past participle. For instance, for the verb bepalen 'to determine', the present tense third person singular is spelled bepaalt, whereas the past participle is spelled bepaald, despite the same pronunciation /bəpa:It/. For the other half of the test verbs, the past tense singular is homophonic with the adjectival past participle. For instance, the past tense singular and the adjectival past participle of the verb verbranden 'to burn' are both pronounced /vərbrandə/, but are spelled verbrandde and verbrande, respectively.

\footnotetext{
1 In general, the fourth year of havo is a rather heterogeneous group as several preparatory educations give access to this level. (i.e., havo3, havo4, vwo3, vwo4, mavo4)
} 
Both homophonic verb forms were presented in the pretest as well as in the posttest. The verb forms were embedded in compound sentences, containing subordinate clauses, which contained the target verb forms, as illustrated in (1). In the first sentence of the example, the target verb form is a present tense form (spelled with $<\mathrm{t}>$ ), in the second sentence a past participle (spelled with $<\mathrm{d}>$ ).

(1) Examples of test sentences (with the target verb forms underlined)

Voor een leraar is het heel belangrijk dat hij zijn aandacht over alle leerlingen verdeelt.

'It is very important for a teacher to pay attention to all students.'

Toen zij de leiding kreeg over dit project, heeft ze de taken niet eerlijk verdeeld.

'After being put in charge of this project, she did not distribute the tasks fairly.'

The test ensured that the third person singular present tense and the past participle of the same verb were at the same place in the sentence (in the middle for half of the verbs, at the end of the sentence for the other half), albeit their grammatical functions differed. While the same verb forms were used in the pre- and the posttest, the sentences were different. We divided the 72 test verbs in two sets and created three master lists for every set, each containing a total of 90 verb forms, of which 72 were test verb forms (i.e., both homophonous verb forms of the 36 test verbs in the set), and 18 filler verb forms. The order of the verb forms was randomized using Mix (van Casteren \& Davis, 2006), with the constraint that a verb form and its homophone counterpart were separated by at least twenty other verb forms. After randomization, we mirrored these master lists replacing one member of the homophone pair with the other member, which resulted in twelve different lists. Each participant received one list in the pretest and one in the posttest, presenting the same test verb forms, but in a different order.

\subsubsection{Procedure}

The pre- and posttests were conducted during regular classes in a normal classroom setting ( 45 minutes at this secondary school), using a web-based program. Before the pretest started, the students were asked to fill out personal information about age, (possible) dyslexia, and mother tongue. In the tests, the sentences were presented one by one. The target verb forms were replaced by dashes followed by the infinitives between brackets. For each target verb form, students had to perform two tasks. First, they were asked to identify the grammatical function of the verb form. Students could choose between present tense (in Dutch persoonsvorm tegenwoordige tijd), past tense (in Dutch persoonsvorm verleden tijd), past participle (in Dutch voltooid deelwoord), infinitive (in Dutch infinitief), and adjectival past participle (in Dutch bijvoeglijk naamwoord). Students should have been introduced to this grammatical terminology as it is part of the curriculum. The option weet niet 'don't know' was added. Second, they were then asked how that form should be spelled. The students' task was to type in the correct form. Each sentence appeared in the 
center of the screen, as did the response that the students typed in, a few lines below the sentence. Both the grammar and spelling task were self-paced and students could continue the tests by pressing <enter > or clicking the <next> button. We built in two one-minute breaks after every thirty sentences. We ensured that the first two trials after each break were fillers. On average, it took the students 33 minutes to finish a test.

One week after the pretest, the verb-spelling courses started. Students received six training sessions, divided over three weeks (i.e., two sessions per week).The posttest was performed one week after the training sessions. In the following, we will describe both spelling courses in more detail.

Traditional verb-spelling instruction (TI)

The $\mathrm{TI}$ verb-spelling course started with three sessions activating prior knowledge regarding all necessary grammatical concepts. At the start of each lesson, the teacher shared the learning objective with the class. Hereafter, the teacher explained what the following concepts entailed: verb, infinitive, stem, tense, subject and number, past participle, adjectival past participle. Grade 10 students should be acquainted with these concepts as they are part of their curriculum. While students were encouraged to participate by asking questions, TI does not make use of small whiteboards. After the instruction several sentences were shown on a screen to the entire class. Students were asked to determine the grammatical functions of several verb forms in these sentences. Each concept was practiced with six different sentences. Students wrote down their answers in their workbooks. After each exercise, the correct answers were shown to the students.

The fourth session focused on spelling of the present tense. The orthographical rules were explained briefly after which students practiced with exercises. We used the textbook Nieuw Nederlands, fifth edition (Frank et al., 2013). The chapter about the present and past tense contains a short flowchart scheme, comparable to an algorithm. Students practiced the exercises by themselves, using the theory in the textbook. The first part of the fifth training session was used to check the exercises.

The fifth training session focused on the spelling of the past tense, and the sixth session on the spelling of the past participle and the adjectival past participle. Exercises that were made during the fifth session, were checked during the sixth session, whereas the final exercises were checked at the end of the sixth session.

In general, the lessons in the TI verb-spelling course elaborated on previous knowledge. Although a brief overview of the pertinent grammatical concepts was given during the first three training sessions, the exercises in the textbook implicitly assumed that students already possess all relevant grammatical knowledge and know how to determine the verb forms' grammatical functions. In one of the exercises, for instance, students were presented sentences for which they had to perform two tasks: They had to identify the grammatical function of a verb form first, after which they had to spell the verb form properly (just like in the pretest and 
posttest of this study). Consequently, students had to rely on previous grammatical knowledge or they had to recall it from the first three training sessions.

Each chapter in the textbook starts with a short overview of the orthographical rules. The first chapter focusses on the spelling rules for present tense and past tense verb forms, the second chapter focusses on all other verb forms (i.e., infinitive, present and past participle, and adjectival past participle). The third chapter focusses only on homophonous verb forms. Both Chapters 1 and 2 contain exercises with incorrectly-spelled verb forms. Students had to explain why the verb forms are incorrect. Chapter 3 contains an exercise where students have to choose between two homophonic forms. The spelling exercises in Nieuw Nederlands are suited for independent processing, but also for working in pairs or cooperative learning. During the phase of independent processing, the teacher walked around the classroom to assist students and students were also allowed to help each other.

\section{Explicit verb-spelling instruction (EDI)}

The EDI verb-spelling course also started with three sessions activating prior knowledge regarding all necessary grammatical concepts. The teacher explained the same grammatical concepts as in the TI course, except that each training session was much more structured, using the gradual release of responsibility model (Pearson \& Gallagher, 1983). This means that the concepts were both explained and practiced, using small whiteboards. After a specific concept was explained, a sentence was shown on a screen to the entire class. First the teacher demonstrated (i.e., modelling) with one or two sentences how a specific grammatical concept could be identified in the sentence. Then the teacher together with the students practiced out loud several more exercises. Finally, students practiced for themselves by writing down their answers on the small whiteboards. This technique was used throughout all the three sessions on grammatical concepts.

In the fourth session, the present tense was the key grammatical concept. To be able to properly spell present tense verb forms, students have to use more grammatical concepts, such as verb, stem, person, tense and number. All these concepts were practiced, using the small whiteboards, before the teacher explained the orthographical rules for present tense verb forms. Again, these rules were explained and practiced using the same set up as in the first three training sessions. The fifth and sixth training session also followed that same set up.

The use of specific techniques as well as the several components of EDI imply that the classes in the EDI course were more structured and interactive than those in the TI course. Furthermore, the teacher more often illustrated and practiced (i.e., modelling), together with the students, the application of the rules, and therefore the relationship between grammar and spelling. Finally, there is more explicit attention for grammar in the EDI course than in the TI course, even for students who already have some basic grammatical knowledge. 


\subsubsection{Analysis}

We analyzed the correctness of the answers to the test verb forms by means of generalized linear mixed effects regression models with the binomial link function in $\mathrm{R}$ version 3.5.3 (R Core Team, 2019), using the Car package (Fox \& Weisberg, 2011) and the Ime4 package (Bates et al., 2015). To account for differences between individual stimuli and subjects, the model contained Subject and Inflected form as crossed random effects. Lemma was left out as random effect as likelihood ratio tests revealed no improvement of the models.

Before we analyzed the effect of the type of instruction, we removed the verb beraden 'to deliberate' from the dataset as the past participle of this verb is not homophonous with the present tense. To examine the effect of the type of instruction on grammatical correctness, a model was fitted with Type of instruction (EDI versus $\mathrm{TI})$, and Test (pretest versus posttest) as fixed effects as well as its interaction. To examine the effect of the type of instruction on spelling correctness, another model was fitted with the aforementioned fixed effects as well as Grammatical correctness (correct identification of the grammatical function) and all possible interactions between the three predictors. Furthermore, we included random slopes if they significantly improved the model fit, as revealed by likelihood ratio tests.

The literature on homophone verb-spelling errors shows that spelling accuracy can be affected by several more variables (e.g., Bryant et al., 1999; Chamalaun et al., 2021; Juul \& Ebro, 2004; Largy et al., 1996; Sandra et al., 1999, 2004). We did not include these additional variables in our main analyses in order to keep the statistical analyses as simple as possible. However, in order to investigate whether these additional variables may interfere with our variables of interest, we ran additional analyses with the additional variables, that is, we analyzed grammatical and spelling performance also including the fixed predictors Grammatical function of the verb form (present tense, past participle, past tense, adjectival past participle), whether the verb form was the first or the second form of the verb in the experimental list, and Relative frequency (log-transformed and centered) of the correct form compared to its homophone counterpart. Frequencies were taken from SUBTLEX-NL (Keuleers et al., 2010).

The full models are incorporated in the Appendix. The models that we report in the text only contain statistically significant effects and interactions as well as statistically non-significant predictors figuring in significant interactions. These sparse models facilitate the interpretation of the statistical results and avoid that variation that could be explained by the statistically significant predictors is assigned to statistically non-significant effects and interactions. The Appendix also shows the models with the additional variables such as Relative frequency. 


\subsection{Results}

In general, all students made fewer errors on the posttest than the pretest. The overall results of the grammar task and the spelling task are portrayed in Table 1, as a function of the type of intervention. This table also includes the results from Experiment 2, which will be discussed in the results section of Experiment 2.

Table 1. Percentage Correct on Spelling and Grammar of the Pretests and Posttests of Secondary-school students (Experiment 1) and University students (Experiment 2). The letter $M$ represents the mean value and SD the standard deviation.

\begin{tabular}{|c|c|c|c|c|c|c|c|c|}
\hline \multirow{3}{*}{ Intervention type } & \multicolumn{4}{|c|}{ Grammar } & \multicolumn{4}{|c|}{ Spelling } \\
\hline & \multicolumn{2}{|c|}{ Pretest } & \multicolumn{2}{|c|}{ Posttest } & \multicolumn{2}{|c|}{ Pretest } & \multicolumn{2}{|c|}{ Posttest } \\
\hline & $M$ & $S D$ & $M$ & $S D$ & $M$ & $S D$ & $M$ & $S D$ \\
\hline & \multicolumn{8}{|c|}{ Secondary-school students } \\
\hline EDI & 60 & 49 & 68 & 47 & 61 & 49 & 65 & 48 \\
\hline \multirow[t]{2}{*}{ TI } & 71 & 45 & 76 & 43 & 64 & 48 & 70 & 46 \\
\hline & \multicolumn{8}{|c|}{ University students } \\
\hline EDI-fpst & 93 & 26 & 95 & 23 & 87 & 33 & 94 & 24 \\
\hline EDI-other & 74 & 44 & 88 & 32 & 75 & 44 & 89 & 31 \\
\hline $\mathrm{TI}$ & 81 & 39 & 90 & 31 & 80 & 40 & 88 & 33 \\
\hline
\end{tabular}

Table 2 presents the final statistical model for grammatical correctness. We only find a significant effect of the type of test: In both groups, students' grammatical mastery improved from pre- to posttest (as indicated by the simple effect of Test). This improvement did not differ significantly between the two types of instruction (no interaction between Test and Type of instruction, which was therefore left out of the model reported in Table 2 , but is present in the model reported in Table $A$ in the Appendix).

Table 2. Experiment 1. Statistical Model for Predicting Grammatical Correctness

\begin{tabular}{llll}
\hline Fixed effects & $\mathbf{B}$ & $\boldsymbol{z}$ & $\boldsymbol{p}$ \\
\hline Intercept & 0.88 & 4.92 & $<.001$ \\
Test: Post & 0.44 & 3.51 & $<.001$ \\
Random effects & SD & & \\
Subject (intercept) & 1.03 & & \\
Test by Subject & 0.53 & \\
Inflected form (intercept) & 0.47 & \\
Test by Inflected form & 0.61 & \\
\hline
\end{tabular}

Note. A positive 8 means that students made fewer mistakes. The intercept represents the pretest. Estimated standard deviation is indicated by SD.

Table 3 presents the final statistical model for spelling correctness. As predicted, the final model showed a significant effect of Grammatical correctness showing that proper identification of the grammatical function of a verb form increased the likelihood that the verb form was spelled correctly. Table 4 displays the percentages of correctly spelled verb forms with respect to whether the grammatical function was 
correctly identified as well. Because the students improved their grammatical skills from pre- to posttest, as indicated by the analysis of the grammatical correctness (see Table 2), this effect of Grammatical correctness shows that the students improved their spelling from pre- to posttest (as shown in Table 1).

The effect of Grammatical correctness indicates that the participants based their spelling of a verb form on the spelling rules, which are based on the verb form's function. This is in line with how the incorrectly identified verb forms were spelled: Many of these were spelled in accordance with the incorrectly identified grammatical function. For instance, when participants in the TI group incorrectly identified a verb form's grammatical function as that of its homophone, they also spelled the verb form as its homophone in 71\% (162 of the 228 incorrectly identified homophones) and 75\% (134 of the 179 incorrectly identified homophones) of cases, in the pretest and posttest, respectively, while they only did so in 16\% (32 of the 199) and $12 \%$ (21 of the 178) of cases, respectively, when they had erroneously assigned another function to the verb forms. According to a Chi-square test, this difference is statistically significant for both the pretest and the posttest (pretest: $\chi^{2}(3,427)=$ $130.5, p<.001$; posttest: $\left.\chi^{2}(3,357)=148.0, p<.001\right)$. Students in the EDI group followed a similar pattern: They spelled the verb forms that were incorrectly associated with the functions of their homophones applying the rules for these homophones in 59\% (128 of the 217 incorrectly identified homophones) and 60\% (101 of the 167 incorrectly identified homophones) of cases, in pretest and posttest, respectively, while they only did so in 16\% (43 of the 261) and 19\% (42 of the 220) of cases, respectively, when they had erroneously assigned another function to the verb forms. According to a Chi-square test, this difference is statistically significant for both the pretest and the posttest (pretest: $\chi^{2}(3,478)=138.55, p<.001$; posttest: $\chi^{2}$ $(3,387)=109.18, p<.001)$.

The statistical analysis for spelling correctness showed a simple effect of Test on top of the effect of Grammatical correctness, showing that the improved performance in the posttest cannot be completely explained by students' improved knowledge of the verb forms' grammatical functions.

Finally, the spelling analysis also revealed an effect of Type of instruction, as well as an interaction between Type of instruction and Grammatical correctness. Together, these two effects show that the EDI students performed in general better than the TI students, but they relied less on their knowledge of the verb forms' functions. This is true for both the pretest and the posttest because there was no statistically significant three-way interaction of Grammatical correctness, Type of instruction and Test (see Table B in the Appendix for the full model).

The statistical analyses with the additional variables showed the same results patterns. Although we found effects on grammatical correctness and spelling correctness from Grammatical function and Relative frequency, these effects had no influence on the variables of interest. The results of these analyses can be found in the Appendix, Tables C and D. 
Table 3. Experiment 1. Statistical Model for Predicting Spelling Correctness

\begin{tabular}{llll}
\hline Fixed effects & $\boldsymbol{B}$ & $\boldsymbol{z}$ & $\boldsymbol{p}$ \\
\hline Intercept & -1.15 & -6.44 & $<.001$ \\
Grammatical correctness & 2.68 & 22.76 & $<.001$ \\
Type of instruction: EDI & 0.50 & 2.01 & $<.05$ \\
Test: Post & 0.23 & 2.16 & $<.05$ \\
Grammatical correctness x Type of instruction: EDI & -0.65 & -4.04 & $<.001$ \\
Random effects & SD & & \\
Subject (intercept) & 0.61 & \\
Test by Subject & 0.34 & \\
Inflected form (intercept) & 0.58 & \\
Test by Inflected form & 0.64 & \\
\hline Note. A positive B means that students made fewer mistakes. The intercept represents the \\
pretest, and TI as type of instruction. Estimated standard deviation is indicated by SD.
\end{tabular}

Table 4. Percentages correctly spelled verb forms categorized by correctness of grammatical identification in the pretest and posttest in Experiments 1 and 2. The letter $M$ represents the mean value and SD the standard deviation.

\begin{tabular}{|c|c|c|c|c|c|c|c|c|}
\hline \multirow{3}{*}{ Intervention type } & \multicolumn{4}{|c|}{ Correct } & \multicolumn{4}{|c|}{ Incorrect } \\
\hline & \multicolumn{2}{|c|}{ Pretest } & \multicolumn{2}{|c|}{ Posttest } & \multicolumn{2}{|c|}{ Pretest } & \multicolumn{2}{|c|}{ Posttest } \\
\hline & $M$ & $S D$ & $M$ & $S D$ & $M$ & $S D$ & $M$ & $S D$ \\
\hline & \multicolumn{8}{|c|}{ Secondary-school students } \\
\hline EDI & 79 & 41 & 81 & 40 & 33 & 47 & 31 & 46 \\
\hline \multirow[t]{2}{*}{$\mathrm{TI}$} & 80 & 40 & 84 & 36 & 24 & 43 & 25 & 43 \\
\hline & \multicolumn{8}{|c|}{ University students } \\
\hline EDI-fpst & 91 & 28 & 98 & 15 & 32 & 47 & 31 & 47 \\
\hline EDI-other & 85 & 36 & 98 & 15 & 46 & 50 & 27 & 44 \\
\hline $\mathrm{TI}$ & 89 & 31 & 95 & 23 & 43 & 50 & 31 & 46 \\
\hline
\end{tabular}

In conclusion, Experiment 1 confirmed that having correctly identified the form's grammatical function is an important predictor for verb form spelling. More importantly for our research question, both groups' grammatical mastery improved as a result of instruction and, accordingly, their spelling skills improved as well. We did not observe any differences between the two instruction groups in how much they improved their grammatical and spelling skills during the intervention. Thus, at this point we can only conclude that both TI and EDI are suitable teaching methods for secondary-school students.

In Experiment 2, we further investigated the hypothesis that EDI outperforms $\mathrm{TI}$ for the spelling of homophonic verb forms, but in this case, we tested proficient spellers (i.e., university students). Empirical evidence showed that grammatical mastery increases as students become older (e.g., Chamalaun et al., 2021), which raised the question what the effects of the type of instruction are at a better grammatical mastery. We expected again that verb-spelling results will be better if the students attended the course that used EDI instead of the course that used TI, because they better learn to employ their grammatical knowledge. 


\section{EXPERIMENT 2}

\subsection{Method}

\subsubsection{Participants}

Thirty-six undergraduates at Radboud University, Nijmegen, took part in the experiment. All participants had Dutch as their native tongue and their mean age was 20.7 years $(S D=5.04)$. The students were asked to participate voluntarily in a spellingcrash-course. The first group $(N=20)$ took the course that used EDI, whereas the second group $(N=16)$ took the course that used TI. Half of the students in the EDI course were studying to become primary-school teachers. They knew beforehand the instruction method would be EDI-based, whereas the other half of the students in the EDI course did not know the instruction method. To prevent a confound, we analyzed the EDI group as if consisting of two separate groups: EDI-fpst (i.e., future primary school teachers; $n=10$ ) and EDI-other (i.e., other students; $n=10$ ). This led to a total of three "instruction groups". One student in the TI course, and six students in the EDI course (1 EDI-fpst; 5 EDI-other) had dyslexia statements. As dyslexia is not equally distributed over the groups, we analyzed possible effects of dyslexia, which we did not observe. We therefore included all participants in our analyses. All students participated in the pretest, posttest, and all four training sessions.

\subsubsection{Materials}

We used the same materials as in Experiment 1.

\subsubsection{Procedure}

We followed the same procedure as in Experiment 1, except that the training started two weeks after the pretest. During the following weeks, students received one training session of 90 minutes every week, because the classes at this university last 90 rather than 45 minutes, as at the secondary school. This meant that one training session at the university equaled two classes at the secondary school. Due to this difference in duration of classes, the training sessions were organized slightly differently than those in Experiment 1. The first training session focused on all necessary grammatical concepts, the second session on the spelling of the present tense and the past tense, the third session on the spelling of the past participle and the adjectival past participle, and the fourth session on some known difficulties, as these students are experienced spellers. The posttest was performed during the second part of the fourth training session. 


\subsubsection{Analysis}

We analyzed the data in the same way as the data from Experiment 1, with one exception: we had three different groups (i.e., EDI-fpst, EDI-other, and TI). Especially the two EDI groups are small, resulting in low statistical power. As a consequence, only large differences among them can be found.

\subsection{Results}

In general, students in all three groups made fewer errors on the posttest than the pretest. The overall results of the grammar task and the spelling task are portrayed in Table 1 (see the results section on Experiment 1), as a function of experimental group. Table 4 shows the percentages of correctly spelled verb forms categorized by correctness of grammatical identification.

As shown in Tables 1 and 4, there are large differences between the two groups who attended the EDI course. Right from the beginning, students who were studying to become primary-school teachers (i.e., EDI-fpst) made fewer errors in spelling as well as in grammar than students who were studying other subjects. This observation legitimized our decision to analyze them as two separate groups.

Table 5 presents the final statistical model for grammatical correctness (see Table E in the Appendix for a full model). As in Experiment 1, all groups improved their grammatical mastery (simple effect of Test), to the same extent (no interaction between Test and Type of instruction). The only difference between the three groups is that the EDI-fpst group had a better grammatical mastery from the beginning.

Table 5. Experiment 2. Statistical Model for Predicting Grammatical Correctness

\begin{tabular}{llll}
\hline Fixed effects & $\boldsymbol{B}$ & $\boldsymbol{Z}$ & $\boldsymbol{p}$ \\
\hline Intercept & 1.97 & 4.89 & $<.001$ \\
Type of instruction: EDI-fpst & 1.11 & 2.11 & $<.05$ \\
Type of instruction: TI & 0.12 & 0.27 & 0.78 \\
Test: Post & 0.67 & 3.00 & $<.01$ \\
Random effects & SD & & \\
Subject (intercept) & 1.39 & \\
Test by Subject & 0.92 & \\
Inflected form (intercept) & 0.82 & \\
Test by Inflected form & 0.87 & & \\
\hline
\end{tabular}

Note. A positive 8 means that students made fewer mistakes. The intercept represents the pretest, and EDI-other as type of instruction. Estimated standard deviation is indicated by SD.

Table 6 presents the final statistical model for spelling correctness. As expected, the final model showed a significant effect of Grammatical correctness, showing that proper identification of the grammatical function of a verb form increased the likelihood that the verb form was properly spelled. This effect of grammatical correctness was much larger in the posttest than in the pretest. This holds for all groups, as 
shown by the three models just differing in which participant group is on the intercept (for the interaction of Test with Grammatical correctness, the model yielded $B$ $=1.64, z=4.21, p<.001$, and $B=1.93, z=2.77, p<.01$, with on the intercept $\mathrm{TI}$ and EDI-fpst, respectively). More importantly for our research question, although the instruction strengthened the relation between grammatical and spelling correctness for all groups, it did less so for the TI group, which showed the smallest increase in the use of grammatical analysis.

The increased impact of the identified verb form's grammatical function on its spelling from pretest to posttest is in line with the results of the additional analyses we performed on the spelling of the verb forms whose grammatical functions were incorrectly identified. When participants identified a verb form's function as that of its homophone counterpart, they tended to spell the verb form accordingly more often in the posttest than in the pretest. Out of the grammatical errors made by the students in the TI group, $35 \%$ in the pretest and $31 \%$ in the posttest were confusions with the verb form's homophone, and in $72 \%$ (54 of the 75 incorrectly identified homophones) and $86 \%$ (32 of the 37 incorrectly identified homophones) of these cases, in the pretest and posttest, respectively, the students spelled the verb form according to their incorrect grammatical identification, that is, as the verb form's homophone. According to a Chi-square test, this difference between pre- and posttest is statistically significant $\left(\chi^{2}(3,112)=45.36, p<.001\right)$.

Similarly, out of the grammatical errors made by the students in the EDI-other group, $38 \%$ (69 of the 183 incorrectly identified homophones) and $42 \%$ (35 of the 83 incorrectly identified homophones), in pretest and posttest, respectively, were confusions with the verb form's homophone. In 58\% (40 of the 69) and $86 \%$ (30 of the 35 ) of these cases, the students also spelled the verb form's homophone. According to a Chi-square test, this difference between pre- and posttest is statistically significant $\left(\chi^{2}(3,104)=25.46, p<.001\right)$.

Finally, out of the grammatical errors made by the students in the EDI-fpst group, $28 \%$ ( 14 of the 50 ) in the pretest and $41 \%$ (16 of the 39 ) in the posttest were confusions with the verb form's homophone and in $43 \%$ ( 6 of the 14) and $63 \%$ (10 of the 16) of these cases, the students spelled the verb form accordingly as the homophone. According to a Chi-square test, this difference is not statistically significant $\left(x^{2}(3,30)=1.47, p=0.69\right)$. These results do not show that the EDI-other group increased their reliance on the grammatical function of the verb form from pre- to posttest more than the other groups, possibly because of lack of statistical power (the number of errors are low).

Perhaps unexpectedly, the simple effect of Test was statistically significant with a negative coefficient rather than with a positive coefficient. The three groups do not differ from each other in this respect as indicated by the absence of statistically significant interactions of Type of instruction with Test. (Note that the absence of differences among the groups may be due to a too small statistical power as the number of grammatical errors is low.) This stresses the greater importance of grammatical correctness in the posttest than in the pretest. The increased performance in the 
posttest, as reflected in Tables 1 and 4, can be fully attributed to the higher correlation between grammatical and spelling correctness in the posttest. Moreover, the negative coefficient of Test shows that if participants incorrectly identified the verb form's grammatical role (incorrect grammatical identification is at the intercept), participants were worse at arriving at the correct spelling in the posttest than in the pretest. They probably applied the spelling rules appropriate for the grammatical function they incorrectly assigned to the verb form, arriving at an incorrect spelling.

Table 6. Experiment 2. Statistical Model for Predicting Spelling Correctness

\begin{tabular}{llll}
\hline Fixed effects & $\boldsymbol{B}$ & $\boldsymbol{z}$ & $\boldsymbol{p}$ \\
\hline Intercept & 0.12 & 0.37 & 0.71 \\
Grammatical correctness & 1.94 & 7.98 & $<.001$ \\
Type of instruction: EDI-fpst & -0.46 & -0.86 & 0.39 \\
Type of instruction: TI & -0.06 & -0.14 & 0.89 \\
Test: Post & -0.90 & -2.10 & $<.05$ \\
Grammatical correctness x Type of instruction: EDI-fpst & 1.25 & 2.69 & $<.01$ \\
Grammatical correctness x Type of instruction: TI & 0.57 & 1.79 & 0.07 \\
Grammatical correctness x Test: Post & 3.26 & 6.50 & $<.001$ \\
Type of instruction: EDI-fpst x Test: Post & 0.67 & 0.89 & 0.38 \\
Type of instruction: TI x Test: Post & 0.18 & 0.33 & 0.74 \\
Grammatical correctness x Type of instruction: EDI-fpst x Test: Post & -1.33 & -1.60 & 0.11 \\
Grammatical correctness x Type of instruction: TI x Test: Post & -1.62 & -2.70 & $<.01$ \\
Random effects & SD & & \\
Subject (intercept) & 0.74 & & \\
Test by Subject & 0.66 & & \\
Inflected form (intercept) & 0.97 & \\
Test by Inflected form & 0.97 & & \\
\hline
\end{tabular}

Note. A positive 6 means that students made fewer mistakes. The intercept represents the pretest, and EDI-other as type of instruction. Estimated standard deviation is indicated by SD.

Like for the results of Experiment 1, we conducted additional analyses on the data of Experiment 2 in order to see whether our statistical results are different when the statistical models also include additional fixed predictors that have been shown in previous experiments to predict spelling correctness for homophonic verb forms or grammatical identification of verb forms. For the dependent variable of grammatical correctness, these additional analyses showed an effect of Grammatical function, whereas no effects from Relative frequency and the order in which the verb forms were presented were found. Importantly, the predictor of Grammatical function did not interact with the variables of interest. For spelling correctness, effects of all three additional variables were found, but, again, these variables did not modulate the effects of the variables of interest, except that the simple effect of Test was no longer significant (see the Appendix, Tables F and G).

In conclusion, Experiment 2 confirmed that a proper identification of the form's grammatical function predicts spelling correctness. Importantly, we found that this effect was stronger in the posttest than in the pretest, but less so for the students 
who received traditional instruction. This result suggests that EDI is a better teaching method to improve verb-spelling performance than $\mathrm{TI}$ for university students.

\section{GENERAL DISCUSSION}

This study investigated whether verb-spelling errors diminish if Explicit Direct Instruction (EDI) is used as teaching approach, rather than traditional instruction (TI), to explicitly clarify the relationship between grammar and verb spelling. This main question was investigated in two intervention studies: One with secondary-school students and one with university students, who are more experienced spellers. The focus was on Dutch homophonous verb forms, as proper spelling of such forms requires grammatical knowledge and these forms typically elicit many spelling errors.

In both intervention studies (Experiments 1 and 2, respectively), we compared EDI with TI. These methods differ in two important aspects. Firstly, in EDI, the learning process is broken down in smaller steps, in which the teacher walks students many times through the application of the verb-spelling rules, applying them to many examples. The teacher also practices the application of the rules jointly with the class, after which the students work, usually in pairs, on exercises. This made the EDI classes more interactive than the TI classes. Secondly, in the EDI course, the grammatical concepts were more often practiced and the teaching of those concepts was more integrated with the teaching of the spelling rules. Given that the TI classes and the EDI classes differed both in interactivity and in the attention paid to the grammatical concepts, our study cannot distinguish between the contributions of these two differences. This could be investigated in future research.

In both experiments, students' ability to identify a verb form's grammatical function was better after intervention. The type of intervention seems not to have affected the increase in performance. This suggests that, for both secondary-school students and university students, the EDI teaching approach for verb spelling does not improve students' grammatical skills more than the TI teaching approach does.

The two experiments also showed that grammatical mastery was a good predictor of the likelihood that a verb form was spelled properly. Further, the importance of grammatical identification appeared from the finding in both Experiments 1 and 2 that, when spellers incorrectly identified the verb form's grammatical function as that of its homophone, they also tended to spell the homophone. This finding of the impact of the identification of a verb form's grammatical function on its spelling is in line with previous evidence in several languages that profound grammatical knowledge increases the likelihood of a correct spelling (e.g., Chamalaun et al., 2021; Juul \& Ebro, 2004; Muter \& Snowling, 1997). Because grammatical mastery of all students improved during the intervention, their spelling performance increased as well.

In Experiment 1, we did not find an effect of the type of training, neither on grammatical nor on spelling performance. One could suggest that is because neither EDI nor TI may be appealing to secondary-school students. This is not very likely, because 
most students told the teacher spontaneously that they quite liked the EDI teaching method. An additional reason for the absence of an effect of training type on spelling performance is that students did not attend all training sessions. For instance, the fourth and fifth training session (i.e., the sessions that dealt with present tense and past tense verb forms) were missed by four of eighteen EDI students. Thus, based on Experiment 1, we cannot establish whether EDI is a better teaching method than $\mathrm{TI}$ to improve verb-spelling performance. Our data only suggest that, in our experimental set-up, EDI was at least as good as TI.

In contrast, in Experiment 2, we did find an effect of training type on spelling performance. All three groups of university students showed a stronger correlation between grammatical mastery and spelling performance after than before they received training. During both types of training, the students thus better learnt how to use their grammatical knowledge. Importantly, the increase in the correlation from pre- to posttest was larger for the EDI students than for the TI students. The EDI course thus appears to do a better job in teaching students how to employ their grammatical knowledge. This confirms our hypothesis that EDI is better than $\mathrm{TI}$ for spelling homophonous verb forms.

While the role of grammatical knowledge increased during the instruction, the use of other verb-spelling strategies not based on grammatical analysis, such as just guessing, seems to be reduced, as indicated by the negative coefficient of the simple effect of the variable Test. If students did not know the verb form's correct grammatical function, they arrived at the correct spelling less often in the posttest than in the pretest, suggesting that they applied the rules appropriate for the grammatical function incorrectly assigned to the verb form, arriving at the incorrect spelling. If the students knew the verb form's grammatical function, they mostly applied the rules based on this grammatical function, arriving at the correct spelling, and did apply alternative strategies less often.

One alternative strategy that they relied on and that was not affected by our intervention is to determine verb spelling without grammatical analysis, and to retrieve that verb form from the mental lexicon that corresponds to the verb form's pronunciation (i.e., retrieval procedure; e.g., Sandra \& Fayol, 2003). Although the retrieval procedure can be helpful for non-homophonous verb forms, it is problematic for homophonous verb forms, because one and the same acoustic form has more than one orthographic representation. The signature of this strategy is the effect of the relative frequency of the verb form and of its homophonous form that we found in the additional analyses for both the secondary-school and the university students. Several studies have documented an increase in bias towards the most frequent form of a homophonous pair (irrespective of which form is correct) when the difference in frequency between the two forms increases. This effect, sometimes referred to as the homophone dominance effect, has been demonstrated in various languages, including Dutch (e.g., Assink, 1985; Bosman, 2005; Frisson \& Sandra, 2002; Sandra et al., 1999, 2004), and French (Bonin \& Fayol, 2002; Largy et al., 1996). The additional analyses we ran in both Experiments 1 and 2 also reveal this bias: They 
also showed an effect of relative frequency, indicating that fewer verb-spelling errors were made the more frequent the verb form was compared to its homophonic counterpart. This effect was irrespective of the verb-spelling instruction. Verb-spelling instruction thus hardly diminished the use of the lexical retrieval route. The strengthening of the correlation between grammatical mastery and spelling performance after instruction therefore likely decreased the role of other spelling strategies, including guessing.

In both experiments, both the pretest and the posttest contained two homophonous forms of each verb. We analyzed whether the likelihood of a correct answer varied as a function of it being the first or the second form of the verb presented in the pretest, respectively the posttest. Experiment 2 showed that fewer spelling errors were made on the second form of a verb than its first form. This suggests that the participants' spelling of the first member of a homophone pair may have affected the spelling of the second. The order of presentation did not affect the identification of the forms' grammatical functions.

Our intervention studies tested small numbers of students, and the groups differed somewhat in their grammatical and spelling knowledge at the pretest. This may have caused the differences found to be small and not always significant. As a result, replication of our experiments is called for.

In conclusion, our experiments indicate that EDI as instructional strategy for teaching grammar and spelling is suitable for secondary-school students as well as university students. Moreover, EDI produced better results than TI for university students learning homophonous verb spelling, thanks to an increase in the correlation strength between grammatical analysis and verb spelling. After instruction, these students made more use of their improved grammatical skills in verb spelling. Our results thus are in line with our hypothesis that the explicit interactivity and the integration of grammar and verb instruction that was inherent to our EDI approach is also beneficial for teaching verb spelling and to students beyond primary-school level, who already possess some grammatical knowledge.

\section{ACKNOWLEDGEMENTS}

This research was supported by the Netherlands Organisation for Scientific Research (NWO) under project number: 023.005.023. We thank three anonymous reviewers for their comments on earlier versions of this article. We are most grateful to the students and staff of "Het Udens College", a school for secondary education, for their participation and cooperation. We also thank Marije Boonstra and Ellen de Man, for conducting the pretests in Experiment 2. 


\section{REFERENCES}

Adams, G.L., \& Engelmann, S. (1996). Research on direct instruction: 25 years beyond distar. Seattle, WA: Educational Achievement System.

Assink, E.M.H. (1985). Assessing spelling strategies for the orthography of Dutch verbs. British Journal of Psychology, 76(3), 353-363. https://doi.org/10.1111/j.2044-8295.1985.tb01958.x

Assink, E.M.H. (1987). Algorithms in spelling instruction: The orthography of Dutch verbs. Journal of Educational Psychology, 79(3), 228-235. https://doi.org/10.1037/0022-0663.79.3.228

Bakker-Peters, M., Zuidema, J., Bosman, A.M.T., \& Neijt, A. (2017). The compatibility of didactic resources and the linguistic logic of spelling in Dutch verb spelling. Tijdschrift voor Taalbeheersing, 39(1), 31-62. https://doi.org/10.5117/TVT2017.1.BAKK

Bates, D., Mächler, M., Bolker, B.M., \& Walker, S.C. (2015). Fitting linear mixed-effects models using Ime4. Journal of Statistical Software, 67, 1-48. https://doi.org/10.18637/jss.v067.i01

Blair, T.R., \& Rupley, W.H. (1988). Practice and application in the teaching of reading. The Reading Teacher, 41, 536-539.

Bonin, P., \& Fayol, M. (2002). Frequency effects in the written and spoken production of homophonic picture names. European Journal of Cognitive Psychology, 14(3), 289-313. https://doi.org/10.1080/ 09541440143000078

Bosman, A.M.T. (2005). Development of rule-based verb spelling in Dutch students. Written Language \& Literacy, 8(1), 1-18. https://doi.org/10.1075/wll.8.1.01bos

Bosse, M., Brissaud, C., \& Le Levier, H. (2020). French pupils' lexical and grammatical spelling from sixth to ninth grade: A longitudinal study. Language and Speech, 1-26. https://doi.org/10.1177/ 0023830920935558

Bryant, P., Nunes, T., \& Aidinis, A. (1999). Different morphemes, same spelling problems: cross-linguistic developmental studies. In M. Harris and G. Hatano (Eds.), Learning to read and write. A cross-linguistic perspective (pp. 112-133). Cambridge: Cambridge University Press.

van Casteren, M., \& Davis, M. H. (2006). Mix, a program for pseudorandomization. Behavior Research Methods, 38(4), 584-589. https://doi.org/10.3758/BF03193889

Chamalaun, R.J.P.M., Bosman, A.M.T., \& Ernestus, M.T.C. (2021). The role of grammar in spelling homophonous regular verbs. Written Language \& Literacy, 24(1), 38-80. https://doi.org/10.1075/ wll.00047.cha

Engelmann, S. \& Carnine. D. (1991). Theory of instruction: Principles and applications. NIFDI Press.

Fielding, G.D., Kameenui, E., \& Gersten, R. (1983). A comparison of an inquiry and a direct instruction approach to teaching legal concepts and applications to secondary school students. The Journal of Educational Research, 76(5), 287-293. https://doi.org/10.1080/00220671.1983.10885468

Fox, J., \& Weisberg, S. (2011). An R companion to applied regression ( $2^{\text {nd }}$ ed). Thousand Oaks, CA: Sage.

Frank, H., Grezel, J.-E., Kooiman, M., Steenbergen, W., \& Zetstra, H. (2013). Nieuw Nederlands, 4/5 havo. Groningen: Noordhoff Uitgevers.

Frisson, S. \& Sandra, D. (2002). Homophonic forms of regularly inflected verbs have their own orthographic representations: A developmental perspective on spelling errors. Brain and Language, 81(13), 545-554. https://doi.org/10.1006/brln.2001.2546

Hänze, M., \& Berger, R. (2007). Cooperative learning, motivational effects, and student characteristics: An experimental study comparing cooperative learning and direct instruction in $12^{\text {th }}$ grade physics class. Learning and Instruction, 17, 29-41. https://doi.org/10.1016/j.learninstruc.2006.11.004

Hattie, J. (2009). Visible learning: A synthesis of over 800 meta-analyses relating to achievement. Abingdon: Routledge.

Hollingsworth, J.R., \& Ybarra, S.E. (2009). Explicit Direct Instruction (EDI): The power of the well-crafted, well-taught lesson. DataWORKS Educations.

Hughes, C.A., Morris, J.R., Therrien, W.J., \& Benson, S.K. (2017). Explicit instruction: Historical and contemporary contexts. Learning Disabilities Research \& Practice, 32(3), 140-148. https://doi.org/10.1111/ldrp.12142

Juul, H., \& Ebro, C. (2004). The links between grammar and spelling: A cognitive hurdle in deep orthographies? Reading and Writing: An Interdisciplinary Journal, 17, 915-942. https://doi.org/ 10.1007/s11145-004-2109-7 
Juul, H. (2005). Grammatical awareness and the spelling of inflectional morphemes in Danish. International Journal of Applied Linguistics, 15, 87-112. https://doi.org/10.1111/j.1473-4192.2005.00082.x

Keuleers, E., Brysbaert, M., \& New, B. (2010). SUBTLEX-NL: A new frequency measure for Dutch words based on film subtitles. Behavior Research Methods, 42, 643-650. https://doi.org/ 10.3758/BRM.42.3.643

Kirschner, P.A., Sweller, J., \& Clark, R.E. (2006). Why minimal guidance during instruction does not work: An analysis of the failure of constructivist, discovery, problem-based, experiential, and inquiry-based teaching. Educational Psychologist, 41(2), 75-86. https://doi.org/10.1207/s15326985ep4102_1

Largy, P., Fayol, M., \& Lemaire, P. (1996). The homophone effect in written French: The case of verb-noun inflection errors. Language and Cognitive Processes, 11(3), 217-255. https://doi.org/10.1080/ 016909696387178

Liem, G.A.D., \& Martin, A.J. (2013). Direct instruction and academic achievement. In J. Hattie \& E. Anderman (Eds.), International Guide to Student Achievement (chapter 5). Oxford: Routledge.

Marzano, R.J., Pickering, D.J., \& Pollock, J.E. (2001). Research-based strategies for increasing student achievement. Association for Supervision \& Curriculum Development.

Muter, V., \& Snowling, M. (1997). Grammar and phonology predict spelling in middle childhood. Reading and Writing: An Interdisciplinary Journal, 9, 407-425. https://doi.org/10.1007/978-94-017-3054-9_6

Nunes, T., Bryant, P., \& Bindman, M. (1997). Learning to spell regular and irregular verbs. Reading and Writing: An Interdisciplinary Journal, 9, 427-449. https://doi.org/10.1023/A:1007951213624

Pearson, P.D., \& Gallagher, M.C. (1983). The instruction of reading comprehension. Contemporary Educational Psychology, 8(3), 317-344. https://doi.org/10.1016/0361-476X(83)90019-X

R Core Team (2019). R: A language and environment for statistical computing. $R$ Foundation for Statistical Computing. Vienna, Austria. Retrieved from https://www.R-project.org/.

Read, D. (1986). Children's Creative Spelling. London: Routledge \& Kegan Paul.

Rosenshine, B.V. (2012). Principles of instruction. American Educator, 36(1), 12-19.

Rupley, W.H., Blair, T.R, \& Nichols, W. (2009). Effective reading instruction for struggling readers: The role of direct/explicit teaching. Reading and Writing Quarterly, 25(2), 125-138. https://doi.org/10.1080/10573560802683523

Sandra, D., \& Fayol, M. (2003). Spelling errors with a view on the mental lexicon: Frequency and proximity effects in misspelling homophonous regular verb forms in Dutch and French. In R.H. Baayen \& R. Schreuder (Eds.), Morphological structure in language processing (pp. 485-514). Berlin: De Gruyter Mouton. https://doi.org/10.1177/0023830920935558

Sandra, D., Frisson, S., \& Daems, F. (1999). Why simple verb forms can be so difficult to spell: The influence of homophone frequency and distance in Dutch. Brain and Language, 68(1-2), $277-283$. https://doi.org/10.1006/brln.1999.2108

Sandra, D., Frisson, S., \& Daems, F. (2004). Still errors after all those years... Limited attentional resources and homophone frequency account for spelling errors on silent verb suffixes in Dutch. Written Language and Literacy, 7(1), 61-77. https://doi.org/10.1075/wll.7.1.07san

Scholfield, P.J. (1994). Writing and spelling: The view from linguistics. In G.D.A. Brown and N.C. Ellis (Eds.), Handbook of spelling: Theory, Process and Intervention (pp. 51-71). Chichester: John Wiley \& Sons.

Shute, V.J. (2008). Focus on formative feedback. Review of Educational Research, 78, 153-189. https://doi.org/10.3102/0034654307313795

Stockard, J., Wood, T.W., Coughlin, C., \& Khoury, C.R. (2018). The effectiveness of direct instruction curricula: A meta-analysis of a half century of research. Review of Educational Research, 88, 479-507. https://doi.org/10.3102/0034654317751919

Veenman, S., Denessen, E., van den Oord, I., \& Naafs, F. (2003). Direct and activating instruction: Evaluation of a preservice course. Journal of Experimental Education, 71(3), 197-225. https://doi.org/10.1080/00220970309602063

Wolfe, P. (1998). Revisiting effective teaching. Educational Leadership, 56(3), 61-64.

Zuidema, J.J. (1988). Efficiënt spellingonderwijs: Een leer- en expertmodel voor het spellen. [Efficient spelling instruction: A learning and expert model for spelling]. Doctoral dissertation Utrecht University, the Netherlands. 


\section{APPENDIX}

Verbs represented in the pretest and posttest as present tense forms and past participles:

beantwoorden 'to answer', behandelen 'to treat', behoren 'to be part of', bekennen 'to confess', benoemen 'to appoint', bepalen 'to determine', beraden 'to deliberate', besparen 'to save', bespieden 'to spy on', besturen 'to drive', betekenen 'to mean', beveiligen 'to secure', bevestigen 'to confirm', bevreemden 'to strange', gebeuren 'to happen', geloven 'to believe', herinneren 'to remember', herkennen 'to recognize', herhalen 'to repeat', herstellen 'te recover', ontaarden 'to degenerate', ontbranden 'to ignite', ontharden 'to soften', onthoofden 'to behead', verbazen 'to amaze', verdedigen 'to defend', verdelen 'to divide', verdienen 'to earn', vergoeden 'to reimburse', verklaren 'to declare', verleiden 'to seduce', vermoeden 'to suspect', vermoorden 'to kill', vertellen 'to tell', vervolgen 'to continue', verwijderen 'to delete'.

Verbs represented in the pretest and posttest as past tense forms and adjectival past participles:

beboeten 'to fine', begeleiden 'to accompany', begroeten 'to greet', begroten 'to estimate', beïnvloeden 'to influence', bekleden 'to dress', belasten 'to tax', bepleiten 'to advocate', berechten 'to trial', bereiden 'to prepare', besteden 'to spend', bestraten 'to pave', bevoorraden 'to supply', bevrijden 'to free', ontbloten 'to uncover', ontkrachten 'to invalidate', ontleden 'to dissect', ontluchten 'to vent', ontmoeten 'to encounter', verafgoden 'to idolize', verblijden 'to rejoice', verblinden 'to dazzle', verbranden 'to burn', verbreden 'to broaden', vergroten 'to enlarge', verharden 'to harden', verkleden 'to disguise', verloten 'to raffle', vermelden 'to mention', verontrusten 'to trouble', verpesten 'to screw up, verplichten 'to oblige', verroesten 'to rust', verspreiden 'to spread', verwachten 'to expect', verwoesten 'to destroy'.

Table A. Experiment 1. Statistical Model for Predicting Grammatical Correctness (full model)

\begin{tabular}{llll}
\hline Fixed effects & $\boldsymbol{B}$ & $\boldsymbol{z}$ & $\boldsymbol{p}$ \\
\hline Intercept & 1.15 & 5.03 & $<.001$ \\
Type of instruction: EDI & -0.61 & -1.81 & 0.07 \\
Test: Post & 0.41 & 2.51 & $<.05$ \\
Type of instruction: EDI x Test: Post & 0.07 & 0.33 & 0.74 \\
Random effects & SD & & \\
Subject (intercept) & 0.98 & & \\
Test by Subject & 0.52 & & \\
Inflected form (intercept) & 0.47 & & \\
Test by Inflected form & 0.61 & & \\
\hline
\end{tabular}

Note. A positive 8 means that students made fewer mistakes. The intercept represents the pretest, and TI as type of instruction. Estimated standard deviation is indicated by SD. 
Table B. Experiment 1. Statistical Model for Predicting Spelling Correctness (full model)

\begin{tabular}{llll}
\hline Fixed effects & $\boldsymbol{B}$ & $\boldsymbol{z}$ & $\boldsymbol{p}$ \\
\hline Intercept & -1.11 & -5.91 & $<.001$ \\
Grammatical correctness & 2.59 & 16.64 & $<.001$ \\
Type of instruction: EDI & 0.52 & 2.03 & $<.05$ \\
Test: Post & 0.24 & 1.16 & 0.24 \\
Grammatical correctness x Type of instruction: EDI & -0.63 & -2.94 & $<.01$ \\
Grammatical correctness x Test: Post & 0.18 & 0.77 & 0.44 \\
Type of instruction: EDI x Test: Post & -0.23 & -0.85 & 0.39 \\
Grammatical correctness x Type of instruction: EDI x Test: Post & -0.02 & -0.08 & 0.94 \\
Random effects & $S D$ & & \\
Subject (intercept) & 0.60 & & \\
Test by Subject & 0.31 & & \\
Inflected form (intercept) & 0.57 & & \\
Test by Inflected form & 0.64 & & \\
\hline Note. $A$ Positive $B$ means that studentsmade fewer mistakes. The intercept represents the
\end{tabular}

Note. A positive 6 means that students made fewer mistakes. The intercept represents the pretest, and TI as type of instruction. Estimated standard deviation is indicated by SD.

Table C. Experiment 1. Statistical Model for Predicting Grammatical Correctness (additional model)

\begin{tabular}{llll}
\hline Fixed effects & $\boldsymbol{B}$ & $\boldsymbol{z}$ & $\boldsymbol{p}$ \\
\hline Intercept & 1.41 & 5.73 & $<.001$ \\
Type of instruction: EDI & -0.61 & -1.80 & 0.07 \\
Test: Post & 0.40 & 2.43 & $<.05$ \\
Grammatical function: Present tense & -0.65 & -5.00 & $<.001$ \\
Grammatical function: Past tense & 0.11 & 0.86 & 0.39 \\
Grammatical function: Past participle & -0.29 & -2.16 & $<.05$ \\
Relative frequency & 0.16 & 1.76 & 0.08 \\
Presentation: Second & -0.11 & -1.59 & 0.11 \\
Type of instruction: EDI x Test: Post & 0.07 & 0.34 & 0.74 \\
Random effects & SD & & \\
Subject (intercept) & 0.99 & & \\
Test by Subject & 0.52 & & \\
Inflected form (intercept) & 0.43 & & \\
Test by Inflected form & 0.61 & & \\
\hline
\end{tabular}

Note. A positive 6 means that students made fewer mistakes. The intercept represents the adjectival past participle, the pretest, first presentation, and TI as type of instruction. Estimated standard deviation is indicated by SD. 
Table D. Experiment 1. Statistical Model for Predicting Spelling Correctness (additional model)

\begin{tabular}{llll}
\hline Fixed effects & $\boldsymbol{B}$ & $\boldsymbol{Z}$ & $\boldsymbol{p}$ \\
\hline Intercept & -1.16 & -5.51 & $<.001$ \\
Grammatical correctness & 2.55 & 16.37 & $<.001$ \\
Type of instruction: EDI & 0.49 & 1.92 & 0.06 \\
Test: Post & 0.24 & 1.16 & 0.25 \\
Grammatical function: Present tense & -0.50 & -3.40 & $<.001$ \\
Grammatical function: Past tense & 0.30 & 2.01 & $<.05$ \\
Grammatical function: Past participle & 0.49 & 3.40 & $<.001$ \\
Relative frequency & 0.28 & 2.81 & $<.01$ \\
Presentation: Second & 0.00 & -0.02 & 0.98 \\
Grammatical correctness x Type of instruction: EDI & -0.56 & -2.62 & $<.01$ \\
Grammatical correctness x Test: Post & 0.19 & 0.84 & 0.40 \\
Type of instruction: EDI x Test: Post & -0.25 & -0.91 & 0.36 \\
Grammatical correctness x Type of instruction: EDI x Test: & -0.03 & -0.10 & 0.92 \\
Post & & & \\
Random effects & SD & & \\
Subject (intercept) & 0.60 & & \\
Test by Subject & 0.32 & & \\
Inflected form (intercept) & 0.42 & & \\
Test by Inflected form & 0.65 & & \\
\hline Note. A positive $B$ means that students made fewer & & \\
\hline
\end{tabular}

Note. A positive 8 means that students made fewer mistakes. The intercept represents the adjectival past participle, the pretest, first presentation, and TI as type of instruction. Estimated standard deviation is indicated by SD.

Table E. Experiment 2. Statistical Model for Predicting Grammatical Correctness (full model)

\begin{tabular}{llll}
\hline Fixed effects & $\boldsymbol{B}$ & $\boldsymbol{z}$ & $\boldsymbol{p}$ \\
\hline Intercept & 1.57 & 3.47 & $<.001$ \\
Type of instruction: EDI-fpst & 1.87 & 2.87 & $<.01$ \\
Type of instruction: TI & 0.57 & 0.99 & 0.32 \\
Test: Post & 1.11 & 3.26 & $<.01$ \\
Type of instruction: EDI-fpst x Test: Post & -0.92 & -1.86 & 0.06 \\
Type of instruction: TI x Test: Post & -0.51 & -1.22 & 0.22 \\
Random effects & SD & & \\
Subject (intercept) & 1.37 & & \\
Test by Subject & 0.85 & & \\
Inflected form (intercept) & 0.82 & & \\
Test by Inflected form & 0.87 & & \\
\hline
\end{tabular}

Note. A positive 6 means that students made fewer mistakes. The intercept represents the pretest, and EDI-other as type of instruction. Estimated standard deviation is indicated by SD. 
Table F. Experiment 2. Statistical Model for Predicting Grammatical Correctness (additional model)

\begin{tabular}{|c|c|c|c|}
\hline Fixed effects & B & $z$ & $p$ \\
\hline Intercept & 2.56 & 5.35 & $<.001$ \\
\hline Type of instruction: EDI-fpst & 1.88 & 2.86 & $<.01$ \\
\hline Type of instruction: TI & 0.56 & 0.97 & 0.33 \\
\hline Test: Post & 1.09 & 3.17 & $<.01$ \\
\hline Grammatical function: Present tense & -1.82 & -9.29 & $<.001$ \\
\hline Grammatical function: Past tense & -1.19 & -6.16 & $<.001$ \\
\hline Grammatical function: Past participle & -0.92 & -4.54 & $<.001$ \\
\hline Relative frequency & 0.11 & 0.84 & 0.40 \\
\hline Presentation: Second & 0.03 & 0.38 & 0.71 \\
\hline Type of instruction: EDI-fpst $x$ Test: Post & -0.94 & -1.88 & 0.06 \\
\hline Type of instruction: TI x Test: Post & -0.50 & -1.20 & 0.23 \\
\hline Random effects & $S D$ & & \\
\hline Subject (intercept) & 1.38 & & \\
\hline Test by Subject & 0.86 & & \\
\hline Inflected form (intercept) & 0.63 & & \\
\hline Test by Inflected form & 0.90 & & \\
\hline
\end{tabular}


Table G. Experiment 2. Statistical Model for Predicting Spelling Correctness (additional model)

\begin{tabular}{|c|c|c|c|}
\hline Fixed effects & B & $z$ & $p$ \\
\hline Intercept & -0.68 & -1.95 & 0.05 \\
\hline Grammatical correctness & 2.04 & 8.44 & $<.001$ \\
\hline Type of instruction: EDI-fpst & -0.53 & -1.00 & 0.32 \\
\hline Type of instruction: $\mathrm{TI}$ & -0.09 & -0.22 & 0.83 \\
\hline Test: Post & -0.73 & -1.67 & 0.09 \\
\hline Grammatical function: Present tense & 0.04 & 0.16 & 0.87 \\
\hline Grammatical function: Past tense & 0.82 & 3.56 & $<.001$ \\
\hline Grammatical function: Past participle & 1.77 & 7.24 & $<.001$ \\
\hline Relative frequency & 0.36 & 2.26 & $<.05$ \\
\hline Presentation: Second & 0.21 & 1.99 & $<.05$ \\
\hline Grammatical correctness x Type of instruction: EDI-fpst & 1.30 & 2.80 & $<.01$ \\
\hline Grammatical correctness $x$ Type of instruction: $\mathrm{TI}$ & 0.54 & 1.71 & 0.09 \\
\hline Grammatical correctness $x$ Test: Post & 3.07 & 6.12 & $<.001$ \\
\hline Type of instruction: EDI-fpst x Test: Post & 0.55 & 0.71 & 0.48 \\
\hline Type of instruction: TI x Test: Post & 0.11 & 0.20 & 0.84 \\
\hline $\begin{array}{l}\text { Grammatical correctness } x \text { Type of instruction: EDI-fpst x } \\
\text { Test: Post }\end{array}$ & -1.18 & -1.40 & 0.16 \\
\hline $\begin{array}{l}\text { Grammatical correctness } x \text { Type of instruction: TI x Test: } \\
\text { Post }\end{array}$ & -1.50 & -2.49 & $<.05$ \\
\hline Random effects & $S D$ & & \\
\hline Subject (intercept) & 0.74 & & \\
\hline Test by Subject & 0.67 & & \\
\hline Inflected form (intercept) & 0.68 & & \\
\hline Test by Inflected form & 0.98 & & \\
\hline
\end{tabular}

Note. A positive 6 means that students made fewer mistakes. The intercept represents the adjectival past participle, the pretest, first presentation, and EDI-other as type of instruction. Estimated standard deviation is indicated by SD. 